\title{
Characterizing practices and resources for inclusive physics learning
}

\author{
Laura A. Wood and Amy D. Robertson \\ Physics Department, Seattle Pacific University, 3307 Third Ave W, Seattle, WA, 98119-1997
}

\begin{abstract}
Fostering inclusive physics learning environments for women and people of color is an important aspect of improving physics culture and teaching. We interviewed physics faculty who are actively working to make their classrooms and departments more inclusive. We characterized the inclusive practices these faculty described themselves as using and the resources - e.g., the knowledge, dispositions, and commitments - that fuel or support their doing so. This paper gives examples of these resources and practices for inclusive physics learning, illustrating both the breadth and richness of resources physics faculty are using and the ways in which those resources are brought to bear in teaching strategies and departmental actions.
\end{abstract}

\section{INTRODUCTION}

Systemic disparities with regard to race, gender, and other identity markers pervade physics, as they do in society at large [1,2]. Physics instructors, education researchers, and professional societies are - and have been - using their voices and their work to strive for more inclusive communities, at local (e.g., classroom) and national (e.g., community-wide) levels (e.g., [3-6]). This paper describes the efforts of six physics faculty to create more inclusive learning environments at their institutions. We start to answer the question: how is the physics community translating growing convictions about the value and importance of a more diverse community into instructional practice, and what resources support such actions? To do so, we characterize some of the inclusive practices that these six physics faculty report using, as well as the resources dispositional, intellectual, environmental, etc. - that support them in doing so. We show that many of the faculty we interviewed are reframing existing instructional approaches (e.g., the use of active learning strategies) as inclusive practices by incorporating knowledge about how students' lived experiences affect their learning, or knowledge that physics is not acultural. Our aim is to enrich our community's awareness [7] of what inclusive practices in physics can look like, enhancing the lens [8] through which we view physics learning and teaching and providing role models for other faculty who wish to make their local contexts more inclusive.

\section{RESEARCH METHODS}

As part of a larger grant, Robertson (second author) interviewed six physics faculty from around the US about their efforts to create more inclusive learning environments in their departments and/or classrooms. These faculty were identified by the grant's PI as trying to enact inclusive practices on the basis of (a) informal conversations about equity, between the PI and faculty, at conferences, and (b) conference presentations about equity and inclusion. All faculty work for universities in the US - four in the Northwest, one in the Midwest, and one in the South. The faculty identified themselves in the following ways: two identify as female and four as male; three identify as people of color; three serve mostly students of color; three work at small four-year institutions, two at large universities, and one at a two-year college; and three hold faculty administrative positions.

Interview participants were asked questions about their (a) instructional and/or (b) departmental practices, depending on their faculty roles. The interview protocol included seven questions; we focus our analysis on only four of them. These four questions from the instructional interview protocol are reproduced below, with parenthetical references to the departmental protocol: (1) What is the gender/racial/ethnic makeup of your physics classes (department)? (2) How do you think gender/race/ethnicity affects physics learning (students' progress through a physics degree), if at all? (3) How does your goal of supporting women and people of color show in your instruction (department's practices)? (4) Why do you care about gender/racial/ethnic diversity in physics?

Wood (first author) transcribed all six interviews, and developed an emergent coding scheme [9] that characterizes both the inclusive practices that the interviewees described and the knowledge, commitments, materials, etc., (i.e., the resources) that seem to support faculty engagement in inclusive practices. Practices are actions done in the service of inclusivity that the faculty member reports trying and reflecting on, not practices the professor would like to try. Resources include knowledge (i.e., something the faculty member has learned from students or from research literature); dispositions (e.g., attitudes or commitments); and materials (e.g., financial resources from their institution). We think of resources as supporting practices, so evidence that something is a resource includes both (i) proximity to a practice in the interviewee's discussion and (ii) plausible links between knowledge, dispositions, etc., and practices depicted in a single interview. After generating a preliminary coding scheme that captured the practices and resources represented in all six interviews, we condensed the scheme, grouping similar practices and resources. The final coding scheme consists of five practices and five resources.

Wood then coded all six interviews. We report three practices and two resources here, choosing those with the clearest evidence of links between resources and practices.

Our small sample size and descriptive characterization are appropriate for our aim of enhancing instructors' and 
administrators' awareness [7], where the practices can serve as illustrations of what is possible, and the resources point to starting places for engaging in this work and inspiring other practices. That many of the practices and resources appeared across multiple interviews enhances the validity and generalizability of this work [7].

\section{PRACTICES FOR INCLUSIVE PHYSICS LEARNING}

In this section, we summarize three inclusive practices described by the faculty we interviewed. Practices not listed due to space constraints are "encourage and implement student feedback," and "recruit a diverse population."

\section{A. Express caring and responsiveness to students}

The practice of "expressing caring and responsiveness to students" includes overt expressions of faculty caring for students as people who are also culturally diverse, as well as intentional efforts to become more culturally competent [10]. All six faculty members referred to such practices in their interviews. Examples of "expressing caring and responsiveness to students" include encouraging good student-teacher relationships, choosing scenarios for physics problems in ways that consider the breadth and limitations of students' experiences, memorizing students' names quickly, writing letters of recommendation for students, inviting students to attend professional development events, and scheduling flexible office hours.

Through these expressions of care and responsiveness, teachers make physics (and physics learning) more accessible and promote a sense of belonging in physics [11]. For example, students being familiar with the physical scenario in a problem and/or participating in professional events can help create a sense of belonging. Further, these efforts imply that individual students' needs, experiences, and expectations are important, in contrast with tacit adherence to taken-for-granted expectations that some students may not know or wish to be held to.

For example, one faculty interviewee said, "I am very deliberate... when I make word problems about my pronoun choice, so it's either you, or I deliberately over-represent 'she' because 'he' is overrepresented everywhere else. I think I should probably sprinkle 'they' more because that tends to be the preferred pronoun for many trans students... [W] hen I teach special relativity, I have a...primer that...I customize for the classes... and I...deliberately put the students' names in it so they can see their name in a physics book." In choosing to respond to his class demographics - and to what is communicated by conventional pronoun usage - by intentionally using "she" and trying to use "they" more, and by including his students" names in a physics book, this faculty member expresses his desire for his students to feel as though they belong in physics.

\section{B. Communicate expectations explicitly}

Two faculty described as inclusive the practice of being explicit about their assumptions about physics teaching and learning, including expectations for student participation. By making their assumptions about school and physics culture transparent, these instructors give students more equitable access and decrease the stress of deciphering implied expectations.

For example, students from dominant groups may have differential access to traditional school culture (e.g., due to alignment with previous family experiences) [12], giving them an often-unrecognized advantage in college classrooms. Overt communication about class expectations and culture can provide more equitable access to otherwise taken-for-granted norms and practices.

Further, the specific assumptions and expectations these teachers described reframe physics more inclusively. For example, one faculty member described the importance of making clear to her students that collaboration is an expected way to participate in physics class. She said, "I think when you create a different culture where everyone's working together and it's about collaboration and figuring out physics as a group, that changes the conversation about how the classroom should look and what are the expectations, and it makes people...feel like they're part of what's going on rather than just... the few people answering the questions that the teacher asks in the class. It's about working together as a class."

A second physics faculty member talked about explicitly framing his tests as learning experiences, by encouraging exam reworks and having a group work portion. He also described his "simple acknowledgment that there are power, privilege, identity, and difference challenges in the classroom, even if [he doesn't] have a solution." This is an active and overt recognition of systems of privilege within physics learning. He went on to discuss how his course works to address these challenges and how his students can work with him to do so.

\section{Use active learning strategies}

Four interviewees included the use of active learning strategies among the ways in which their instruction is meant to support inclusive learning. Examples of such strategies are captured in one interviewee's depiction of her class, including "lab activit[ies]...where [students are] taking data and analyzing and answering questions," "clicker questions," and "group work."

These faculty described active learning strategies as inclusive largely because of their variety. In other words, active learning strategies provide diverse ways of learning to students and a broader set of tools for instructors, offering more opportunities to respond to the specific needs of their students.

For example, one faculty member said that in developing the department's redesigned physics curriculum, a goal was 
"active learning for most of the class session." She went on to say that "we want to increase the number of tools in the toolbox specifically around effective engagement and report of students from historically underrepresented groups, so we want the faculty to think the toolbox has to be different because the student isn't a little you." In other words, she considers it important that instructors see that there are many different ways students can learn, countering the (perhaps tacit) assumption that students will learn in the same ways faculty did.

\section{RESOURCES FOR INCLUSIVE PHYSICS PRACTICES}

In this section, we describe two of the resources that we inferred as supporting the inclusive practices above, including plausible links between these resources and practices. As above, we think of resources as knowledge, dispositions, and materials that support faculty in engaging in inclusive practices. (The examples we describe in this section are in the form of knowledge.) Resources not listed due to space constraints are "commitment to justice" (dispositional resource), "desire to honor a breadth of student skills" (dispositional resource) and "knowledge that privilege grants access to institutional (and other nonphysics) resources."

\section{A. Knowledge that lived experience affects physics learning}

All six of the faculty we interviewed recognize that students' lived experiences affect their physics learning. In particular, they articulated that (i) stress from microaggressions [13], stereotype threat [14], and impostor syndrome [15] can limit cognitive and social capacity, and that (ii) access to particular life experiences (e.g., playing sports, working on electronics, observing ocean waves) can differentially advantage students as they interact with the substance of the physics course.

For example, one faculty member said, "[Some people might argue that] it's just this [physics] problem in front of me and if only all these other distractions would go away...I have this sort of joke about, well, science would be fine if it only weren't for people...All of this oppression - these constant micro-aggressions against you - are wearing away at your psychic capacity, [and] we're asking [students] to take on a big cognitive load [in learning physics]... So...that activation of stereotype threat happens all the time. And ...I think thinking happens in our brain - I don't think it happens out there - and our brains are in our bodies, and our embodied experience is related to our interactions with other people."

As another example, an interviewee said, "When we talk about when you're on an airplane and you notice this thing or when you're at the beach and you see waves, that presupposes a certain access to experiences that's not generally true. I had a student who had never lived in a house that had a porch before, and one of the homework problems had something about how a ball rolled off a porch, and she just didn't know even what that meant. There's a question on the Calculus Concept Inventory about a redwood tree and one of the ways that you can [eliminate] one of the answers is because it presupposes that you have some notion about the height of a tree in a forest."

Connection between resource and inclusive practices. The sentiments expressed in this latter quote tie to this faculty member's use of active learning strategies. He went on to say, "I try to make sure that we have a lot of hands-on lab experience so that we actually have shared experiences that we can refer to, instead of "when you went to the beach." This resource - knowledge that lived experience affects learning - could also tie to the practice "expressing caring and responsiveness," by, for example, considering diverse backgrounds when writing physics problems.

\section{B. Knowledge that physics learning is not acultural}

Four interviewed faculty explicitly acknowledged that physics - and, by extension, physics learning - is not acultural. These faculty reflected on what physics culture has historically valued, commenting that these cultural values disproportionately advantage certain groups of students (and disadvantage others). These faculty further advocated for appreciating and leveraging the unique perspectives of students from historically marginalized groups, not only to improve these students' experience, but also to problematize what counts as physics.

For example, one faculty member said, "I think the culture of physics is kind of a White male culture and it's how White males interact with each other and then that isn't really a comfortable culture for other people. So I think that's part of what makes it hard for women to...persis[t] in something that isn't totally comfortable."

Another faculty member said, "I think there's [often] this feeling that ...our job is to help our students fit into the existing culture of science [rather than our job being to] ...elevate... and identify the resources that our students have that should really make their way into the science culture and change the science culture. ...I think [the latter is] a really important thing and...figuring out what are the strengths that our students have that we are lacking in the science community...I really respect all the community resources that our students have - the way they talk to each other, the way where they're comfortable with each other..." He went on to comment that physics is often thought of as "something a group of people typically do," but that the way collaboration happens "can be problematic, you know, how we moderate those discussions and how different people are given status." $\mathrm{He}$ observes that the conversations his (majority Black) students have as they do science seem much healthier, and that we - as a physics community - have something to learn from them. 
Connection between resource and inclusive practices. This resource is likely tied to the practice "communicate expectations explicitly." For example, the first quote in this section was immediately followed by the first quote from the "communicate expectations explicitly" section above. This faculty directly tied her choice to frame physics learning as collaborative to her sense that physics, as historically represented, sends cultural messages about who belongs.

The resource "knowledge that physics learning is not acultural" could also support faculty "use of active learning strategies." In the example for that practice, the faculty member said, "we want the faculty to think the toolbox has to be a little different because the student isn't a little you," so the practice of using active learning strategies can be in response to the resource of knowing that there is more than one way of doing physics. This resource seems likely to fuel the use of active learning strategies, because by doing so, teachers set up their classrooms in a way less like the traditional view of physics as "one-size-fits-all."

\section{DISCUSSION}

This paper characterizes some of the practices that physics faculty characterize as inclusive, as well as the resources that support them in enacting these practices in their classrooms and departments. We do not attempt to comprehensively describe every inclusive practice that these faculty (and others) are using. Rather, the paper is meant (i) to provide examples of inclusive practices faculty describe using, as inspiration for other faculty, and (ii) to show ways in which various resources support these practices.

Most of the practices we report were not framed by faculty as overt responses to systems of unfair advantage, although both resources we report indicate knowledge about such inequities. In general, faculty framed inclusive practices in terms of improving learning experiences for all students.

[1] K. Rosa and F.M. Mensah, Phys Rev PER 12, $020113-$ 1 (2016).

[2] R.S. Barthelemy, M. McCormick, and C. Henderson, Phys Rev PER 12, 020119-1 (2016).

[3] https://www.aapt.org/aboutaapt/organization/upload/ AAPT-CoDP_ImprovingDiversityReport February2017-final.pdf. Retrieved 5/31/2017.

[4] https://www.aps.org/policy/statements/08_2.cfm. Retrieved 5/31/2017.

[5] A. Nelson, Phys Today 70, 10 (2017).

[6] A.L. Traxler, X.C. Cid, J. Blue, and R. Barthelemy, Phys Rev PER 12, 020114-1 (2016).

[7] J.A. Maxwell, Harvard Educ Rev 62, 279 (1992).

[8] C. Goodwin, Am Antropol 96, 606 (1994).

[9] K. Krippendorff, Content Analysis: An Introduction to Its Methodology (Sage, Thousand Oaks, 2013).
In fact, many of these practices were depicted as "good teaching," augmented by consideration of how certain practices or content might particularly support students from historically marginalized groups - e.g., active learning strategies provide diverse entry points for learning. Such framings are aligned with literature on multiculturalism (e.g., [16]), more than, for example, anti-racist pedagogies (e.g., [17]).

In other words, these faculty have found ways to take up existing teaching strategies - strategies that do not explicitly attend to race, culture, and gender - and implement them in ways that do attend to these facets of students' identities. Another approach that faculty could take is to develop new pedagogies and strategies that overtly disrupt systems of unfair advantage in physics, drawing on the knowledge resources we describe in this paper.

One implication of this research for physics faculty is that they may already be employing practices that could serve inclusive physics learning. Supporting faculty in developing or drawing on the resources we describe could shape the way faculty enact those practices, without requiring drastic changes to their teaching. As a next step, the community might also consider how we could disrupt existing, unfair systems of privilege, in ways that directly translate the knowledge described by faculty in our interviews into practice.

\section{ACKNOWLEDGEMENTS}

This work was supported in part by National Science Foundation grant 1611318 . We gratefully acknowledge the helpful feedback from W. Tali Hairston, Rachel E. Scherr, and three anonymous reviewers. We are thankful to Rebekah Davis for her administrative support. We are deeply indebted to the six faculty members who shared their perspectives with us.

[10] G. Ladson-Billings, Am Educ Res J 32, 465 (1995).

[11] C. Good, A. Rattan, and C.S. Dweck, J Pers Soc Psychol 102, 700 (2012).

[12] D.J. Wren, Adolescence 34, 593 (1999).

[13] D.W. Sue et al., Am Psychol 62, 271 (2007).

[14] C.M. Steele, Am Psychol 52, 613 (1997).

[15] P.R. Clance and S.A. Imes, Psychother: Theory, Res, Prac 15, 241 (1978).

[16] J.A. Banks, An Introduction to Multicultural Education (Allyn and Bacon, Boston, 1994).

[17] S.M. Lawrence and B.D. Tatum, Teach Coll Rec 99, 162 (1997). 